Revue bibliographique pour le domaine irano-aryen

Volume 37-38-39 | 2018

Comptes rendus des publications de 2014-2016

\title{
Seth Priestman. "The Silk Road or the Sea? Sasanian and Islamic Exports to Japan"
}

\section{Rémy Boucharlat}

\section{(2) OpenEdition}

1 Journals

\section{Édition électronique}

URL : http://journals.openedition.org/abstractairanica/47245

DOI : 10.4000/abstractairanica.47245

ISBN : 1961-960X

ISSN : 1961-960X

Éditeur :

CNRS (UMR 7528 Mondes iraniens et indiens), Éditions de l'IFRI

Référence électronique

Rémy Boucharlat, "Seth Priestman. "The Silk Road or the Sea? Sasanian and Islamic Exports to Japan" », Abstracta Iranica [En ligne], Volume 37-38-39 | 2018, document 78, mis en ligne le 30 décembre 2018, consulté le 26 septembre 2020. URL : http://journals.openedition.org/ abstractairanica/47245 ; DOI : https://doi.org/10.4000/abstractairanica.47245

Ce document a été généré automatiquement le 26 septembre 2020.

Tous droits réservés 


\title{
Seth Priestman. "The Silk Road or the Sea? Sasanian and Islamic Exports to Japan"
}

\author{
Rémy Boucharlat
}

\section{RÉFÉRENCE}

Seth Priestman. "The Silk Road or the Sea? Sasanian and Islamic Exports to Japan", Journal of Islamic Archaeology 3/1, 2016, p. 1-35

1 L'A. spécialiste de la céramique sassanide et islamique, particulièrement en Iran et dans le golfe Persique, fait un point précis sur le commerce du verre et de la poterie produite dans le sud de la Mésopotamie exportés en Extrême Orient. Il conclut, contre l'opinion traditionnelle, que ces exportations étaient faites par voie maritime, alternative à «la Route [les routes] de la Soie » terrestre. Dans cette mise au point très bienvenues, une des questions très débattue depuis plusieurs années est la date des premières productions de la céramique à glaçure turquoise «sassanido-islamique » - mais quand dans la période sassanide ? - de plus en plus fréquente à l'époque islamique en Iraq, dans le golfe Persique et le monde l'Océan indien, Afrique orientale incluse. L'A. montre de plus qu'il faut distinguer plusieurs phases chronologiques internes dans cette production, avec des différences marquées en particulier par l'introduction du décor appliqué au début du VIII $\mathrm{e}$. d.n.è.

2 Plus connues, les importations au Japon de vases en verre à décor taillé de facettes, sont datées surtout de la période $\mathrm{V}^{\mathrm{e}}-\mathrm{VII}{ }^{\mathrm{e}} \mathrm{s}$., comme par exemple dans le trésor impérial de Shōsōin, constitué seulement au VIII ${ }^{e}$ s. Plusieurs pièces trouvées sont très semblables à des vases trouvés en Mésopotamie, dans le Gilan et maintenant dans le Caucase. Puis, la céramique à glaçure turquoise du Moyen-Orient commence à être exportée en Extrême-Orient à l'époque islamique, près d'un siècle après les dernières exportations de verres, lesquelles sont cependant encore employées et échangées à l'intérieur du 
Japon. Cette céramique est la seule catégorie exportée au Japon et est habituellement représentée par des jarres de moyennes ou grandes dimensions. Elle est donc probablement exportée pour son contenant, peut-être le sirop de dattes suggère prudemment l'A. Son inventaire précis des lieux de découverte au Japon lui permet de faire l'hypothèse d'une relation de ces jarres, souvent trouvées à proximité de temples, avec les régions où les communautés bouddhistes étaient actives.

\section{AUTEURS}

RÉMY BOUCHARLAT

UMR 5133 CNRS-Université de Lyon 